\title{
Prospective Study on the Incidence of Postoperative Venous Thromboembolism in Korean Patients with Colorectal Cancer
}

\section{Eunyoung Lee, $M D^{1,2}$ \\ Sung-Bum Kang, $\mathrm{MD}, \mathrm{PhD}^{3}$ \\ Sang II Choi, MD, PhD ${ }^{4}$ \\ Eun Ju Chun, MD ${ }^{4}$ \\ Min Jeong Kim, $\mathrm{RN}^{1}$ \\ Duck-Woo Kim, MD, PhD ${ }^{3}$ \\ Heung-Kwon $\mathbf{O h}, \mathrm{MD}^{3}$ \\ Myong Hoon Ihn, MD \\ Jin Won Kim, MD'1 \\ Soo-Mee Bang, MD, PhD ${ }^{1}$ \\ Jeong-Ok Lee, MD \\ Yu Jung Kim, MD, PhD' \\ Jee Hyun Kim, MD, PhD' \\ Jong Seok Lee, MD, PhD ${ }^{1}$ \\ Keun-Wook Lee, MD, PhD'}

${ }^{1}$ Department of Internal Medicine,

Seoul National University Bundang Hospital, Seoul National University

College of Medicine, Seongnam,

${ }^{2}$ Hematologic Oncology Clinics,

Center for Specific Organs Cancer,

National Cancer Center, Goyang,

Departments of ${ }^{3}$ Surgery and ${ }^{4}$ Radiology,

Seoul National University Bundang Hospital, Seoul National University

College of Medicine, Seongnam, Korea

Correspondence: Keun-Wook Lee, MD, PhD Department of Internal Medicine,

Seoul National University Bundang Hospital,

Seoul National University College of Medicine,

82 Gumi-ro 173beon-gil, Bundang-gu,

Seongnam 13620, Korea

Tel: 82-31-787-7037

Fax: 82-31-787-4098

E-mail: hmodoctor@snubh.org

Received August 17, 2015

Accepted October 27, 2015

Published Online November 17, 2015

${ }^{*}$ Eunyoung Lee and Sung-Bum Kang

contributed equally to this work.

*This paper was presented at the 25th Congress of the International Society of Thrombosis and Haemostasis in Toronto, Canada, June 20-25, 2015.

\section{Purpose}

Pharmacologic thromboprophylaxis is routinely recommended for Western cancer patients undergoing major surgery for prevention of venous thromboembolism (VTE). However, it is uncertain whether routine administration of pharmacologic thromboprophylaxis is necessary in all Asian surgical cancer patients. This prospective study was conducted to examine the incidence of and risk factors for postoperative VTE in Korean colorectal cancer (CRC) patients undergoing major abdominal surgery.

\section{Materials and Methods}

This study comprised two cohorts, and none of patients received perioperative pharmacologic thromboprophylaxis. In cohort A $(n=400)$, patients were routinely screened for VTE using lower-extremity Doppler ultrasonography (DUS) on postoperative days 5-14. In cohort $B(n=148)$, routine DUS was not performed, and imaging was only performed when there were symptoms or signs that were suspicious for VTE. The primary endpoint was the VTE incidence at 4 weeks postoperatively in cohort $A$.

\section{Results}

The postoperative incidence of VTE was 3.0\% $(n=12)$ in cohort A. Among the 12 patients, eight had distal calf vein thromboses and one had symptomatic thrombosis. Age $\geq 70$ years (odds ratio [OR], 5.61), $\geq 2$ comorbidities (OR, 13.42), and white blood cell counts of $>10,000 / \mu \mathrm{L}(\mathrm{OR}, 17.43)$ were independent risk factors for postoperative VTE $(p<0.05)$. In cohort B, there was one case of VTE $(0.7 \%)$.

\section{Conclusion}

The postoperative incidence of VTE, which included asymptomatic cases, was $3.0 \%$ in Korean CRC patients who did not receive pharmacologic thromboprophylaxis. Perioperative pharmacologic thromboprophylaxis should be administered to Asian CRC patients on a riskstratified basis.
Key words

Asia, Colorectal neoplasms, Incidence, Colorectal surgery, Venous thromboembolism 


\section{Introduction}

Studies on cancer-associated venous thromboembolism (VTE) have encompassed a variety of perspectives, including incidence rates, related risk factors, prophylaxis, and treatment, for a range of tumors. Although few prospective studies have investigated the incidence of and risk factors for VTE in Asian patients, it is generally accepted that Asian cancer patients have a lower risk of VTE development compared with Western patients [1-7]. Guidelines from Western countries recommend perioperative pharmacologic thromboprophylaxis for all surgical cancer patients [8-10]. However, given the low VTE incidence in Asian patients, it is not certain whether these VTE guidelines are entirely applicable to Asian cancer patients. Therefore, the applicability of Western guidelines to Asian cancer patients may need to be reappraised.

Because the incidence of colorectal cancer (CRC) has shown a recent rapid increase in some Asian countries [11], the incidence and risk factors associated with surgery-related VTE in Asian patients with CRC should be examined. Therefore, we conducted this prospective study on Korean CRC patients who were undergoing major abdominal surgery.

\section{Materials and Methods}

\section{Patient population}

Between September 2011 and March 2014, 1,166 patients underwent major abdominal surgery for CRC at Seoul National University Bundang Hospital (SNUBH). The definition of major surgery was an open or laparoscopic surgical procedure under general anesthesia that lasted $>30$ minutes [9]. The patients were screened for their eligibility to participate in this prospective study.

The eligibility criteria were patients with pathologically confirmed adenocarcinomas of the colorectum and who had undergone major curative or palliative abdominal cancer surgery and were $\geq 20$ years old. None of the patients were administered perioperative pharmacologic anticoagulation for VTE prophylaxis. Mechanical prophylaxis (elastic stockings or bandages) was allowed, but pneumatic compression was not used at our institution. The exclusion criteria were as follows: concurrent VTE at the time of admission for CRC surgery; a previous or concomitant malignancy, with the exception of patients who were disease-free for $>5$ years; a history of VTE; a known congenital thrombophilia or hypercoagulable state; pregnancy; comorbidities requiring antico- agulation therapy during the perioperative period, for example, cerebrovascular infarcts or atrial fibrillations; and a history of taking antiplatelet or other anticoagulant agents within 2 days of the CRC surgery.

Of the 1,166 patients screened for study eligibility, 567 $(49 \%)$ agreed to participate in this study, and written informed consent was obtained from the patients; however, 19 patients were ineligible to participate and 548 patients were finally included (Fig. 1). When the written informed consents were obtained, all of the enrolled patients agreed to undergo postoperative Doppler ultrasonography (DUS) of the lower extremities to screen for deep vein thrombosis (DVT). However, after acquiring the informed consents, some patients did not undergo the planned DUS; the main reasons for not undergoing DUS were scheduling conflict or change of mind because some patients had already been discharged from hospital before the scheduled DUS. Therefore, cohort A (DUS cohort, $\mathrm{n}=400$ ) included patients who had undergone postoperative DUS, and cohort B (observation cohort, $\mathrm{n}=148$ ) included patients who had not undergone DUS. Data regarding patients' demographics, comorbidities, and laboratory test results before surgery were collected. The D-dimer levels were determined using an immunoturbidimetry assay (STA-Liatest D-Di, Stago, Asniéres sur Seine, France) with a cutoff value of $0.5 \mu \mathrm{g} / \mathrm{mL}$ [12]. Data regarding the surgical procedures were also collected. For patients with localized tumors (stages 1-3), the tumor stages were based on the final pathology reports. Some rectal cancer patients who underwent preoperative chemoradiation had their tumors staged clinically.

\section{Study procedures}

In cohort A, Duplex and color DUS of the lower extremities was performed routinely on all patients 5-14 days after the operation, regardless of the development of symptoms that were suspicious for VTE. The DUS examination was performed from the distal 3-4 cm of the external iliac vein to the distal calf vein. Detection of DVT using DUS was previously described in detail [2].

Although patients in cohort B did not undergo postoperative DUS, the other procedures performed during the study period were the same as those performed on patients in cohort A. VTE-related symptoms and signs were checked during admission for surgery and during follow-up assessments in the outpatient clinic. Both cohorts of patients underwent routine follow-up assessments 4 weeks (window period, \pm 1 week) after surgery, and assessments were then performed every 3-6 months. DUS or computed tomography (CT) angiography assessments of the lower extremities or pulmonary vasculature were performed when symptoms or signs that were suspicious for VTE were detected. 


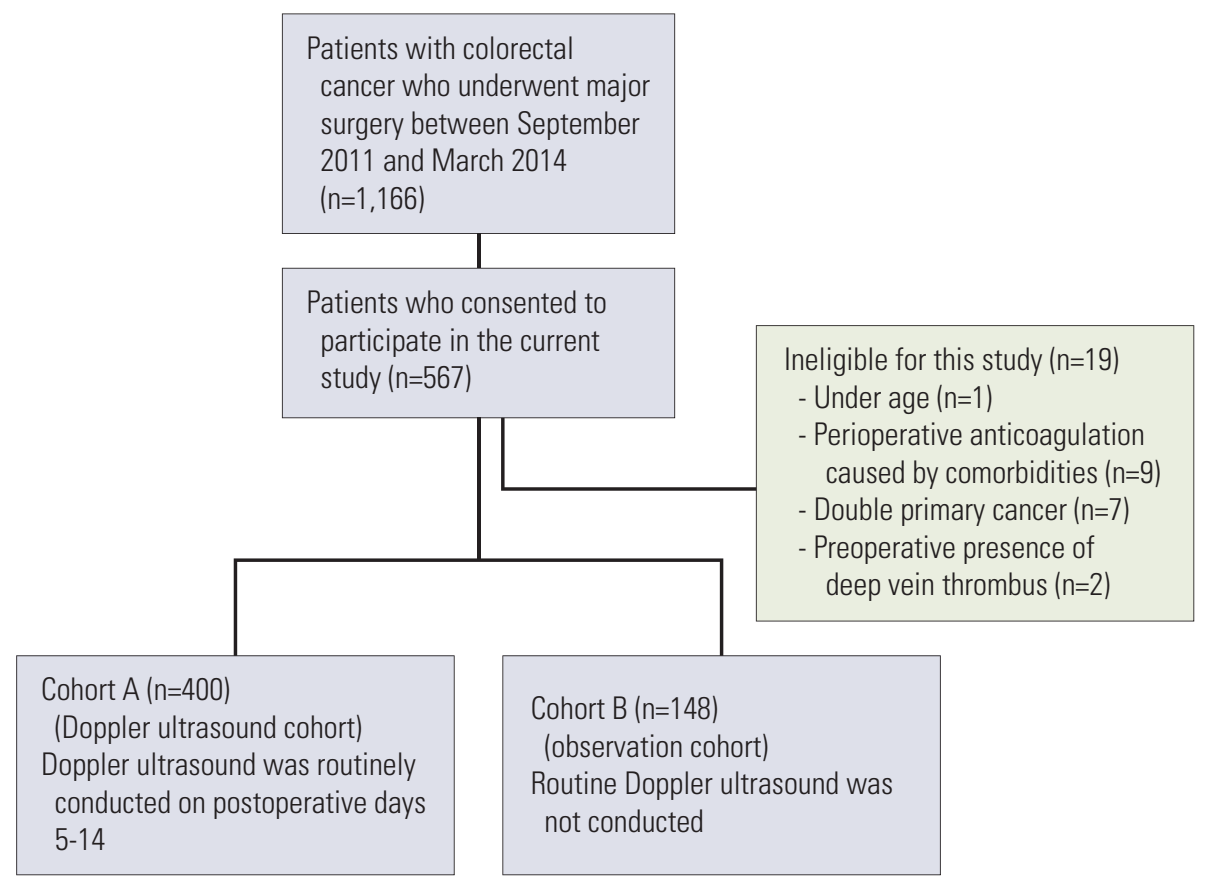

Fig. 1. Flow diagram of the study.

\section{Statistical analyses}

The primary endpoint of the study was the incidence of postoperative VTE, which included asymptomatic and symptomatic cases, in cohort A. The incidence of postoperative VTE was defined as cases identified with VTE using routinely performed DUS on postoperative days 5-14 plus any additional postoperative VTE cases that included DVT or pulmonary embolism (PE) detected using DUS or other imaging modalities until 4 weeks after surgery. The secondary endpoint was to determine the risk factors for postoperative VTE in cohort A. Assuming that the actual postoperative VTE incidence would be approximately 7\% [1] and that this incidence would be $<10 \%$ with statistical significance, 400 patients were required in cohort $\mathrm{A}$ to attain $80 \%$ power and a two-sided significance level of 0.05 .

Statistical analyses were performed using IBM SPSS ver. 21 for Windows (IBM Co., Armonk, NY). Chi-square tests or linear-by-linear association tests were used for comparison of the percentages in the cross-tabulations. Student's $t$ test was applied for comparison of the means between groups. Logistic regression models were used for the multivariate analyses to identify risk factors associated with development of postoperative VTE. Two-sided p-values $<0.05$ were considered statistically significant.

\section{Ethical considerations}

This study was approved by the Institutional Review Board at SNUBH (study number: B1105/128-005), and it was registered with ClinicalTrials.gov (NCT01567917). Written informed consent was obtained from the patients prior to study entry, and this study was conducted in accordance with the principles of the Declaration of Helsinki.

\section{Results}

\section{Patients' characteristics}

Of the 548 patients enrolled in this study, 400 patients were assigned to cohort A (DUS cohort) and 148 patients to cohort B (observation cohort) (Fig. 1). The characteristics of patients in both groups are shown in Table 1. Laparoscopic surgery was performed in $72.6 \%$ of the patients $(398 / 548)$. Approximately half of the patients had no comorbidities, and the primary tumor location was the rectum in approximately $40 \%$ of the patients. Preoperative chemotherapy or radiotherapy was administered to $13.9 \%$ of the patients $(76 / 548)$.

There was no difference in most clinical characteristics between groups. However, compared with patients in cohort 
Table 1. Patients' characteristics

\begin{tabular}{|c|c|c|c|}
\hline Variable & Cohort A $(n=400)$ & Cohort B (n=148) & p-value \\
\hline Age, median (range, yr) & $64(21-95)$ & $65(33-89)$ & $0.582^{\mathrm{a})}$ \\
\hline \multicolumn{4}{|l|}{ Sex } \\
\hline Male & $248(62.0)$ & $79(53.4)$ & $0.078^{\mathrm{b})}$ \\
\hline Female & $152(38.0)$ & $69(46.6)$ & \\
\hline BMI & $23.04 \pm 3.29$ & $23.38 \pm 3.48$ & $0.296^{\mathrm{a})}$ \\
\hline \multicolumn{4}{|l|}{ No. of comorbidities } \\
\hline 0 & $196(49.0)$ & $79(53.4)$ & $0.139^{c)}$ \\
\hline 1 & $124(31.0)$ & $49(33.1)$ & \\
\hline$\geq 2$ & $80(20.0)$ & $20(13.5)$ & \\
\hline White blood cell count $(/ \mu \mathrm{L})$ & $6,058 \pm 2,137$ & $5,951 \pm 1,791$ & $0.560^{\mathrm{a})}$ \\
\hline Hemoglobin $(\mathrm{g} / \mathrm{dL})$ & $12.6 \pm 1.8$ & $12.4 \pm 2.1$ & $0.274^{\mathrm{a})}$ \\
\hline Platelet count $(/ \mu \mathrm{L})$ & $241 \pm 77$ & $251 \pm 74$ & $0.153^{\mathrm{a})}$ \\
\hline D-dimer $(\mu \mathrm{g} / \mathrm{mL})$ & $0.92 \pm 1.80$ & $0.94 \pm 1.60$ & $0.894^{\mathrm{a})}$ \\
\hline$<0.5$ & $174(43.5)$ & $67(45.3)$ & $0.719^{\mathrm{c})}\left(0.673^{\mathrm{d})}\right)$ \\
\hline$\geq 0.5$ & $140(35.0)$ & $59(39.9)$ & \\
\hline Not checked & $86(21.5)$ & $22(14.9)$ & \\
\hline \multicolumn{4}{|l|}{ Tumor stage } \\
\hline $0-1$ & $72(18.0)$ & $37(25.0)$ & $0.010^{\mathrm{a})}$ \\
\hline 2 & $83(20.8)$ & $42(28.4)$ & \\
\hline 3 & $174(43.5)$ & $55(37.2)$ & \\
\hline 4 & $71(17.8)$ & $14(9.5)$ & \\
\hline \multicolumn{4}{|l|}{ Tumor location } \\
\hline Right colon cancer ${ }^{\mathrm{e})}$ & $80(20.0)$ & $35(23.6)$ & $0.296^{\mathrm{c})}$ \\
\hline Left colon cancer ${ }^{\mathrm{f})}$ & $147(36.8)$ & $55(37.2)$ & \\
\hline Rectal cancers) & $173(43.2)$ & $58(39.2)$ & \\
\hline \multicolumn{4}{|l|}{ Histologic differentiation } \\
\hline WDAC & $39(9.8)$ & $16(10.8)$ & $0.701^{\mathrm{c})}$ \\
\hline MDAC & $319(79.8)$ & $114(77.0)$ & \\
\hline PDAC & $29(7.2)$ & $11(7.4)$ & \\
\hline Others & $13(3.2)$ & $7(4.7)$ & \\
\hline \multicolumn{4}{|l|}{ Preoperative treatment } \\
\hline None & $344(86.0)$ & $128(86.5)$ & $0.935^{c)}$ \\
\hline Chemotherapy & $14(3.5)$ & $3(2.0)$ & \\
\hline CCRT & $42(10.5)$ & $17(11.5)$ & \\
\hline Operation time (min) & $194.8 \pm 100.5$ & $175.6 \pm 85.2$ & $0.027^{\mathrm{a})}$ \\
\hline \multicolumn{4}{|l|}{ Operation type } \\
\hline Open & $121(30.2)$ & $29(19.6)$ & $0.013^{\mathrm{b})}$ \\
\hline Laparoscopy & $279(69.8)$ & $119(80.4)$ & \\
\hline
\end{tabular}

Values are presented as number $(\%)$ or mean \pm standard deviation unless otherwise indicated. BMI, body mass index; WDAC, well differentiated adenocarcinoma; MDAC, moderately differentiated adenocarcinoma; PDAC, poorly differentiated ade-

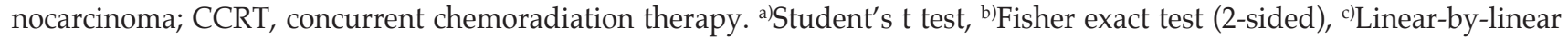
association, ${ }^{d)}$ Fisher exact test excluding the missing data, ${ }^{\text {e) }}$ Right colon cancer included primary tumors located in the cecum, ascending colon, hepatic flexure, and transverse colon, ${ }^{\text {f) }}$ Left colon cancer included primary tumors located in the splenic flexure, descending colon, and sigmoid colon, ${ }^{g}$ Rectal cancer included primary tumors located in the rectum or rectosigmoid junction. 
$\mathrm{B}$, patients in cohort A had tumors at more advanced stages $(\mathrm{p}=0.010)$, and underwent open abdominal surgery more frequently $(\mathrm{p}=0.013)$, and had longer operation times $(\mathrm{p}=0.027)$. Although statistically insignificant, cohort A included more male patients than cohort $B(p=0.078)$.

\section{Postoperative VTE development in cohort A}

In cohort $\mathrm{A}$, the median time to discharge after surgery was 9 days (range, 3 to 51 days). There was no postoperative mortality. In cohort A, $99.5 \%$ of the patients $(398 / 400)$ were followed up at 4 weeks (window period, \pm 1 week) and $98.5 \%$ $(394 / 400)$ were followed up at 12 weeks postoperatively. The postoperative VTE incidence at 4 weeks, which was the primary endpoint, was 3.0\% (12/400) $(95 \%$ confidence interval [CI], $1.6 \%$ to $5.2 \%$ ).

Of the 12 patients who developed postoperative VTE, only one patient $(0.3 \%)$ had symptomatic thrombosis. This patient had underlying congestive heart failure and showed no evidence of DVT during the initial DUS performed routinely on day 6; however, as the edema in both lower extremities was aggravated, a repeat DUS was performed, which detected thromboses in both calf veins on day 13. Regarding the locations of VTE, eight patients had distal calf vein thromboses (7 asymptomatic cases and 1 symptomatic case), three patients had asymptomatic proximal DVT, and one patient had asymptomatic PE. In the patient with postoperative PE, no DVT was detected and the PE was found incidentally on an abdominal CT scan performed on postoperative day 15 to assess postoperative complications. The detailed characteristics of the VTE events are shown in Table 2. Low-molecular weight heparin (LMWH) was administered to three of four asymptomatic patients who had PE or proximal DVT, and one patient with an asymptomatic popliteal vein thrombosis rejected further management of DVT and was lost to follow up. Of the seven patients with asymptomatic calf vein thromboses, LMWH was administered to one patient. LMWH was not administered to the six remaining patients with asymptomatic calf vein thromboses, and VTE recurrence or progression was not observed during the follow-up assessments, which comprised a minimum of 29 days and a maximum of 618 days.

\section{Postoperative VTE development in cohort B}

All 148 patients in cohort B were followed up at 4 weeks (window period, \pm 1 week) and $98.0 \%$ of the patients $(145 / 148)$ were followed up at 12 weeks postoperatively. Only one case of VTE $(0.7 \%)$ was detected postoperatively in cohort B. This patient had stage IV rectal cancer and symptomatic PE and DVT from the left common iliac vein to the calf vein, which were detected simultaneously 12 days after pelvic exenteration.

\section{Univariate and multivariate analyses}

Results from univariate analyses to determine the risk factors associated with postoperative development of VTE in cohort A are shown in Table 3. Age $\geq 70$ years, increased numbers of comorbidities, white blood cell (WBC) counts of $>10,000 / \mu \mathrm{L}$, and elevated D-dimer levels of $\geq 0.5 \mu \mathrm{g} / \mathrm{mL}$ had increased risk of VTE development (all p-values $<0.05$ ). The patient's sex, tumor stage, and other clinical parameters were not predictive of postoperative VTE development.

Multivariate analyses were performed using two methods (Tables 4 and 5). The first method included only the four variables that showed statistical significance in the univariate analyses; age, number of comorbidities, WBC counts, and D-dimer levels (Table 4). Age $\geq 70$ years (vs. $<70$ years) (odds ratio [OR], 5.61; 95\% CI, 1.02 to 30.91; $\mathrm{p}=0.048)$, $\geq$ two comorbidities (vs. no comorbidities) (OR, 13.42; 95\% CI, 1.38 to 130.88; $\mathrm{p}=0.025$ ), and $\mathrm{WBC}$ counts $>10,000 / \mu \mathrm{L}$ (vs. $\leq 10,000 / \mu \mathrm{L})(\mathrm{OR}, 17.43 ; 95 \% \mathrm{CI}, 2.76$ to $109.96 ; \mathrm{p}=0.002)$ were independent risk factors for postoperative VTE. While an elevated preoperative D-dimer level was associated with increased development of postoperative VTE $(\mathrm{OR}, 5.01)$, the association was not statistically significant $(\mathrm{p}=0.147)$. The second method used in performing multivariate analyses included all of the clinical parameters that could be measured or examined preoperatively (Table 5), and all of the variables shown in Table 3, except the operation time and the surgical outcomes (R0, R1, and R2), were included. The results from the second method did not differ from those generated using the first method; hence, age $\geq 70$ years, $\geq$ two comorbidities, and WBC counts of $>10,000 / \mu \mathrm{L}$ were independent risk factors for postoperative VTE.

\section{Discussion}

To the best of our knowledge, this is the largest prospective study of the incidence of VTE following major abdominal surgery in Asian CRC patients. Our findings clearly demonstrate that the incidence of postoperative VTE in Korean CRC patients is lower than that in Western patients.

Without thromboprophylaxis, the VTE incidence, which is based on objective diagnostic screening for asymptomatic DVT, is approximately 15\%-40\% among Western patients who undergo general surgery [10], and even with pharmacologic thromboprophylaxis, the postoperative VTE incidence is approximately $10 \%$ or more in Western CRC patients who undergo surgery $[13,14]$. When limited to cases 


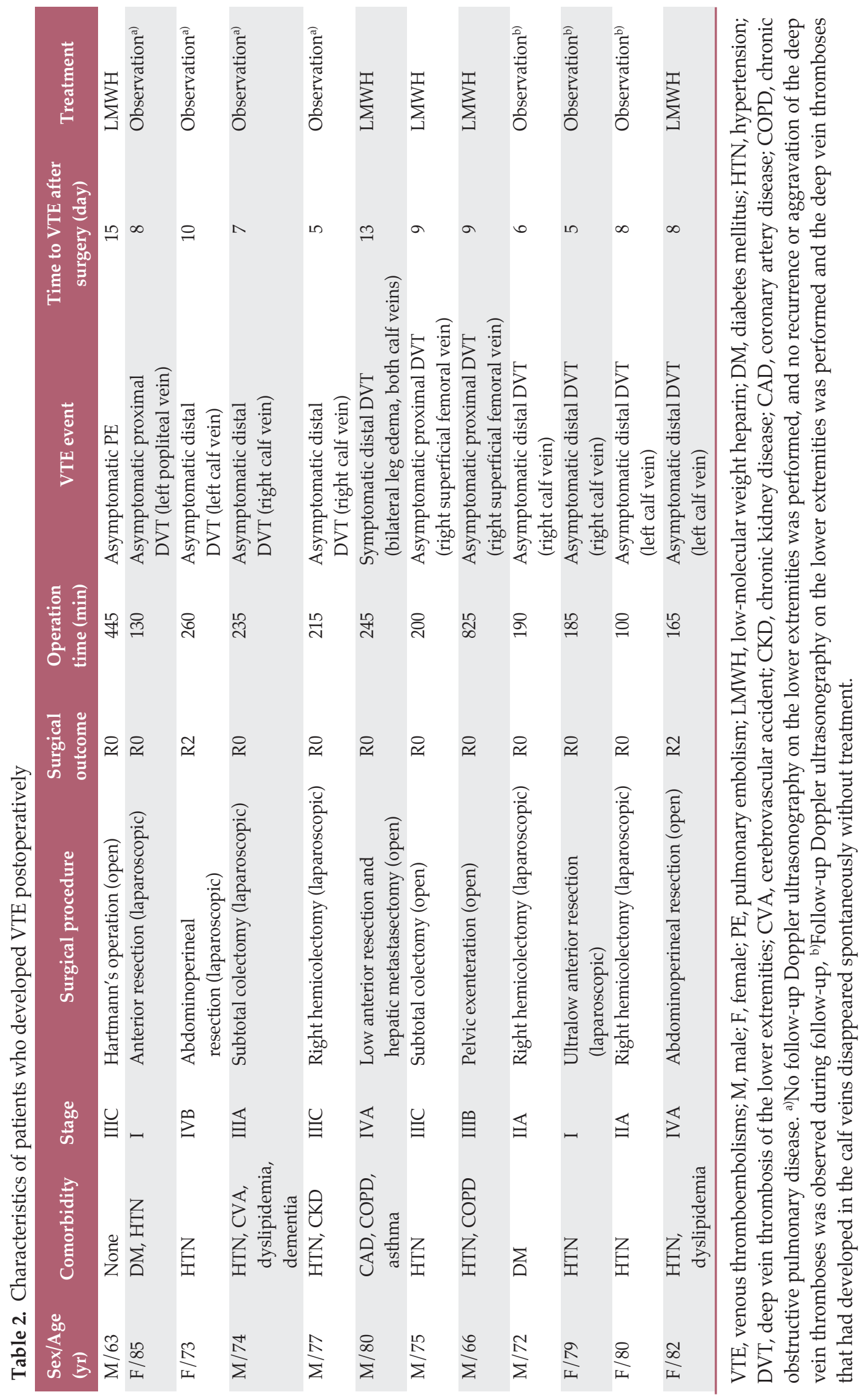


Table 3. Incidence of VTE according to the clinical parameters

\begin{tabular}{|c|c|c|c|}
\hline Variable & VTE $(-)(n=388)$ & VTE $(+)(n=12)$ & p-value \\
\hline \multicolumn{4}{|l|}{ Age (yr) } \\
\hline$<70$ & $252(99.2)$ & $2(0.8)$ & $0.001^{\text {a) }}$ \\
\hline$\geq 70$ & $136(93.2)$ & $10(6.8)$ & \\
\hline \multicolumn{4}{|l|}{ Sex } \\
\hline Male & $241(97.2)$ & $7(2.8)$ & $0.772^{\mathrm{a})}$ \\
\hline Female & 147 (96.7) & $5(3.3)$ & \\
\hline \multicolumn{4}{|l|}{ BMI, mean $\left(\mathrm{kg} / \mathrm{m}^{2}\right)$} \\
\hline$<25$ & $297(97.1)$ & $9(2.9)$ & $1.000^{\mathrm{a})}$ \\
\hline$\geq 25$ & $91(96.8)$ & $3(3.2)$ & \\
\hline \multicolumn{4}{|l|}{ No. of comorbidities } \\
\hline 0 & 195 (99.5) & $1(0.5)$ & $0.001^{\mathrm{b})}$ \\
\hline 1 & $119(96)$ & $5(4)$ & \\
\hline$\geq 2$ & $74(72.5)$ & $6(7.5)$ & \\
\hline \multicolumn{4}{|c|}{ White blood cell count $(/ \mu \mathrm{L})$} \\
\hline$\leq 10,000$ & $369(97.6)$ & $9(2.4)$ & $0.023^{\mathrm{a})}$ \\
\hline$>10,000$ & $19(86.4)$ & $3(13.6)$ & \\
\hline \multicolumn{4}{|c|}{ Hemoglobin level (g/dL) } \\
\hline$<10.0$ & $32(94.1)$ & $2(5.9)$ & $0.271^{\text {a) }}$ \\
\hline$\geq 10.0$ & $356(97.3)$ & $10(2.7)$ & \\
\hline \multicolumn{4}{|l|}{ Platelet count $(/ \mu \mathrm{L})$} \\
\hline$\leq 400,000$ & $375(97.2)$ & $11(2.8)$ & $0.352^{\mathrm{a})}$ \\
\hline$>400,000$ & $13(92.9)$ & $1(7.1)$ & \\
\hline \multicolumn{4}{|l|}{ D-dimer $(\mu \mathrm{g} / \mathrm{mL})$} \\
\hline$<0.5$ & $173(99.4)$ & $1(0.6)$ & $0.003^{b)}\left(0.006^{c}\right)$ \\
\hline$\geq 0.5$ & $131(93.6)$ & $9(6.4)$ & \\
\hline Not checked & $84(97.7)$ & $2(2.3)$ & \\
\hline \multicolumn{4}{|l|}{ Tumor stage } \\
\hline $0-1$ & $70(97.2)$ & $2(2.8)$ & $0.614^{\mathrm{b})}$ \\
\hline 2 & $81(97.6)$ & $2(2.4)$ & \\
\hline 3 & $169(97.1)$ & $5(2.9)$ & \\
\hline 4 & $68(95.8)$ & $3(4.2)$ & \\
\hline \multicolumn{4}{|l|}{ Tumor location } \\
\hline Right colon cancere) & $77(96.2)$ & $3(3.8)$ & $0.761^{\mathrm{b})}$ \\
\hline Left colon cancerf) & $143(97.3)$ & $4(2.7)$ & \\
\hline Rectal cancerg) & $168(97.1)$ & $5(2.9)$ & \\
\hline \multicolumn{4}{|c|}{ Histologic differentiation } \\
\hline WDAC & $39(100)$ & 0 & $0.415^{\mathrm{b})}$ \\
\hline MDAC & $309(96.9)$ & $10(3.1)$ & \\
\hline PDAC & $27(93.1)$ & $2(6.9)$ & \\
\hline Others & $13(100)$ & 0 & \\
\hline \multicolumn{4}{|l|}{ Preoperative treatment } \\
\hline None & $333(96.8)$ & $11(3.2)$ & $0.661^{\mathrm{b})}$ \\
\hline Chemotherapy & $14(100)$ & 0 & \\
\hline CCRT & $41(97.6)$ & $1(2.4)$ & \\
\hline Operation time (min) & $193 \pm 96$ & $266 \pm 196$ & $0.220^{\mathrm{d})}$ \\
\hline \multicolumn{4}{|l|}{ Operation type } \\
\hline Open & $117(96.7)$ & $4(3.3)$ & $0.759^{\text {a) }}$ \\
\hline Laparoscopy & 271 (97.1) & $8(2.9)$ & \\
\hline
\end{tabular}


Table 3. Continued

\begin{tabular}{|c|c|c|c|}
\hline Variable & VTE (-) (n=388) & VTE $(+)(n=12)$ & p-value \\
\hline Surgical outcome & & & $0.648^{\mathrm{b})}$ \\
\hline R0 & $341(97.2)$ & $10(2.8)$ & \\
\hline $\mathrm{R} 1$ or $\mathrm{R} 2$ & $47(95.9)$ & $2(4.1)$ & \\
\hline
\end{tabular}

Values are presented as number $(\%)$ or mean \pm standard deviation. VTE, venous thromboembolisms; BMI, body mass index; WDAC, well differentiated adenocarcinoma; MDAC, moderately differentiated adenocarcinoma; PDAC, poorly differenti-

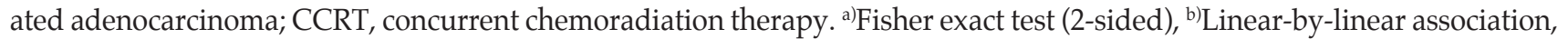

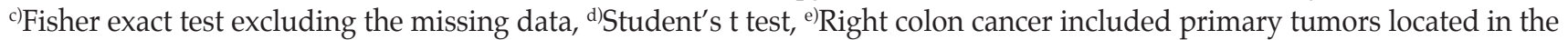
cecum, ascending colon, hepatic flexure, and transverse colon, ${ }^{\mathrm{f}}$ Left colon cancer included primary tumors located in the splenic flexure, descending colon, and sigmoid colon, ${ }^{g}$ Rectal cancer includes primary tumors located in the rectum or rectosigmoid junction.

with symptomatic or proximal DVT and PE, the latest American College of Chest Physicians (ACCP) guideline estimates a VTE incidence of 3\%-6\% among Western CRC patients who undergo major abdominal surgery (moderate to high risk for postoperative VTE development) [15].

The incidence of postoperative VTE in Asian cancer patients is generally known to be lower than that in Western patients [1-7]. The incidence of postoperative VTE in CRC patients ranged from $0.18 \%$ to $0.85 \%$ in retrospective singleinstitution studies conducted in Korea and Hong Kong [4-6,16]. A nationwide Korean population-based study estimated the postoperative VTE incidence as $1.67 \%$ [7]. It has been assumed that most VTE cases detected in these retrospective studies $[4-7,16]$ were symptomatic DVT or PE cases. The ninth ACCP guideline classifies surgical patients according to very low- $(<0.5 \%)$, low- (approximately $1.5 \%)$, moderate- (approximately 3.0\%), and high-risk (approximately $6.0 \%$ ) groups, depending on the estimated baseline incidence of postoperative VTE, which includes proximal or symptomatic DVT plus PE, without thromboprophylaxis. The guideline recommends perioperative pharmacologic thromboprophylaxis for surgical patients who are at moderate-to-high risks for VTE [15]. In this study, the rates of symptomatic VTE were $0.3 \%$ in cohort A and $0.7 \%$ in cohort $\mathrm{B}$, which are within the ranges reported from previous Asian retrospective studies [4-7,16], and are much lower than the VTE rate of $3 \%$ at which routine perioperative pharmacologic thromboprophylaxis is recommended [15]. The eighth ACCP guideline recommends perioperative thromboprophylaxis when the incidence of postoperative VTE is expected to be $\geq 10 \%$, based on objective diagnostic screening for asymptomatic DVT in patients who were not administered thromboprophylaxis [10]. Again, in this study, the postoperative VTE incidence, which included asymptomatic cases in cohort A, was only $3.0 \%$ (95\% CI, $1.6 \%$ to $5.2 \%)$, significantly lower than the recommended VTE incidence level for perioperative pharmacologic thromboprophylaxis in the eighth ACCP guideline. Although the suboptimal sensitivity of DUS as a DVT screening modality may have underestimated the postoperative DVT incidence compared with venography, no additional cases of VTE were detected during the 3-month follow-up period in our study. In addition, DUS has been used increasingly to screen for DVT in recent studies [14]; therefore, we do not think that using DUS to screen for postoperative DVT was a flaw in our study.

Although Western guidelines recommend perioperative pharmacologic thromboprophylaxis for all surgical cancer patients [8-10], the findings of the current study suggest that routine perioperative pharmacologic thromboprophylaxis is not required by all Asian CRC patients who are undergoing major surgery. In this study, all patients routinely received mechanical prophylaxis using elastic stockings or bandages. Therefore, mechanical prophylaxis is thought to be sufficient for prevention of postoperative VTE in Korean CRC patients. Our findings strongly suggest that the risk-stratified use of perioperative pharmacologic thromboprophylaxis is required for Asian cancer patients who are undergoing surgery. The risk-stratified use of perioperative pharmacologic thromboprophylaxis was also suggested by the findings from our previous study of Korean patients with gastric cancer [2]. In the current study, age $\geq 70$ years, $\geq$ two comorbidities, and increased WBC counts of $>10,000 / \mu \mathrm{L}$ independently predicted the increased risk of development of postoperative VTE in CRC patients. Older age [8-10,17], comorbidities $[9,10,17]$, and leukocytosis [9] are well-known risk factors for VTE in cancer patients. Previous studies have proposed D-dimer as a biomarker that can predict development of VTE in cancer patients [18,19]. Stender et al. [19] reported that preoperative plasma D-dimer was a predictor of postoperative DVT in Danish patients with CRC. How- 
Table 4. Multivariate analysis on the postoperative development of venous thromboembolisms

\begin{tabular}{lccc} 
Variable & Odds ratio & $95 \%$ Confidence interval & p-value \\
Age $(\mathbf{y r})$ & & & - \\
$\quad<70$ & 1.00 & - & 0.048 \\
$\quad \geq 70$ & 5.61 & $1.02-30.91$ & 0.070 \\
No. of comorbidities & & & - \\
$\quad 0$ & 1.00 & - & 0.132 \\
1 & 5.61 & $0.60-52.80$ & 0.025 \\
\hline 2 & 13.42 & $1.38-130.88$ & - \\
White blood cell count $(/ \boldsymbol{\mu L})$ & - & - & - \\
$\quad \leq 10,000$ & 1.00 & - & 0.002 \\
$>10,000$ & 17.43 & $2.76-109.96$ & 0.223 \\
D-dimer $(\mu \mathrm{g} / \mathrm{mL})$ & & & - \\
$\quad<0.5$ & 1.00 & - & 0.147 \\
$\quad \geq 0.5$ & 5.01 & $0.57-44.28$ & 0.651 \\
\hline Not checked & 1.82 & $0.14-24.57$ & \\
\hline
\end{tabular}

The four variables that showed statistical significance in the univariate analyses were included.

ever, in the current study, an elevation of the D-dimer level was predictive of postoperative VTE in the univariate analysis, but its statistical significance was not proven in the multivariate analysis. Given the high OR of 5.01 for patients with high preoperative D-dimer levels of $\geq 0.5 \mu \mathrm{g} / \mathrm{mL}$, the lack of statistical significance relating to the D-dimer levels in our patient cohort may be attributed to the lower numbers of VTE events in our study compared with those in the Danish study [19]. An advanced tumor stage is generally considered a risk factor for VTE, but there was no association between the tumor stage and development of postoperative VTE in our patient cohort, which might be explained by an insufficient sample size for verification of the real differences in the VTE rates among patients with tumors at different stages. It remains controversial whether laparoscopic surgery for CRC influences the risk of postoperative VTE compared with open surgery. In our study, the postoperative VTE rates did not differ between patients who underwent laparoscopic surgery and those who underwent open surgery (Table 3), and this finding concurs with the conclusion from a previous metaanalysis [20]. One recent prospective Japanese study investigated the VTE incidence following laparoscopic surgery for gastrointestinal cancer. Of 71 patients enrolled, 35 patients had CRC and neoadjuvant treatment (chemotherapy or chemoradiotherapy) was associated with development of postoperative VTE [21]. However, preoperative chemotherapy or chemoradiotherapy was not predictive of postoperative VTE in our study. Therefore, more studies are necessary to verify risk factors related to postoperative VTE in Asian CRC patients.

Although this study was conducted at a single institution, which could be considered a limitation, because most cancer surgeries are performed at several tertiary high-volume centers in Korea, the situation at other Korean institutions is likely similar to that reported here [2]. Therefore, our results can be generalized to all CRC patients in Korea. However, caution must be exercised. While the findings from several investigations conducted in other Asian countries concur with those of our study $[3,5,6]$, some studies have reported development of postoperative VTE in the absence of perioperative thromboprophylaxis in considerable numbers of CRC patients, even in Asian countries [21-24]. Recent prospective studies have reported that the VTE incidence after abdominal surgery in Japanese patients is not low, compared with Western patients [21,22]; in these Japanese studies, which enrolled patients with CRC or other gastrointestinal or pelvic cancers, the incidence of postoperative VTE was 18\%-24\%. However, most cases with postoperative VTE had asymptomatic calf vein thromboses [21-24], for which the necessity of anticoagulation therapy is controversial. As mentioned above, in our study, among seven patients who developed asymptomatic calf vein thromboses, six patients did not receive anticoagulation therapy and VTE progression was not observed during follow-up (Table 2). Sakon et al. [22] suggested that Westernized dietary habits and lifestyle, trends of more extensive surgeries performed in aged patients, and frequent use of indwelling central venous catheters might be underlying mechanisms of increasing tendency toward VTE formation in Japanese patients. One recent study also demonstrated a yearly increasing incidence of VTE in the Korean population [25]. Therefore, the incidence of VTE may be influenced by socioeconomic or public health status even in the same soci- 
Table 5. Multivariate analysis on the postoperative development of venous thromboembolisms

\begin{tabular}{|c|c|c|c|}
\hline Variable & Odds ratio & 95\% Confidence interval & p-value \\
\hline \multicolumn{4}{|l|}{ Age (yr) } \\
\hline$<70$ & 1.00 & - & - \\
\hline$\geq 70$ & 7.43 & $1.06-51.95$ & 0.043 \\
\hline \multicolumn{4}{|l|}{ Sex } \\
\hline Male & 1.00 & - & - \\
\hline Female & 0.92 & $0.23-3.67$ & 0.900 \\
\hline \multicolumn{4}{|l|}{ BMI } \\
\hline$<25$ & 1.00 & - & - \\
\hline$\geq 25$ & 0.93 & $0.17-5.01$ & 0.935 \\
\hline No. of comorbidities & & & 0.063 \\
\hline 0 & 1.00 & - & - \\
\hline 1 & 8.10 & $0.63-104.35$ & 0.109 \\
\hline$\geq 2$ & 22.59 & $1.53-333.47$ & 0.023 \\
\hline \multicolumn{4}{|l|}{ White blood cell count $(/ \mu \mathrm{L})$} \\
\hline$\leq 10,000$ & 1.00 & - & - \\
\hline$>10,000$ & 17.96 & $2.45-131.87$ & 0.005 \\
\hline \multicolumn{4}{|l|}{ Platelet count $(/ \mu \mathrm{L})$} \\
\hline$\leq 400,000$ & 1.00 & - & - \\
\hline$>400,000$ & 7.43 & $0.43-128.12$ & 0.168 \\
\hline \multicolumn{4}{|l|}{ Hemoglobin concentration (g/dL) } \\
\hline$\geq 10.0$ & 1.00 & - & - \\
\hline$<10.0$ & 1.30 & $0.17-9.84$ & 0.801 \\
\hline D-dimer level $(\mu \mathrm{g} / \mathrm{mL})$ & & & 0.303 \\
\hline$<0.5$ & 1.00 & - & - \\
\hline$\geq 0.5$ & 4.44 & $0.48-41.34$ & 0.191 \\
\hline Not checked & 1.68 & $0.10-27.87$ & 0.717 \\
\hline Tumor stage & & & 0.967 \\
\hline $0-1$ & 1.00 & - & - \\
\hline 2 & 0.55 & $0.06-5.52$ & 0.611 \\
\hline 3 & 0.72 & $0.10-5.06$ & 0.738 \\
\hline 4 & 0.68 & $0.06-8.03$ & 0.756 \\
\hline Tumor location & & & 0.923 \\
\hline Right colon cancer & 1.00 & - & - \\
\hline Left colon cancer & 0.85 & $0.15-4.93$ & 0.853 \\
\hline Rectal cancer & 1.18 & $0.20-7.00$ & 0.855 \\
\hline \multicolumn{4}{|l|}{ Histology } \\
\hline WDAC/MDAC & 1.00 & - & - \\
\hline PDAC/Others & 1.48 & $0.16-13.52$ & 0.729 \\
\hline \multicolumn{4}{|l|}{ Preoperative treatment } \\
\hline No & 1.00 & - & - \\
\hline Yes (chemotherapy or CCRT) & 1.10 & $0.09-13.22$ & 0.938 \\
\hline \multicolumn{4}{|l|}{ Operation type } \\
\hline Laparoscopic & 1.00 & - & - \\
\hline Open & 0.85 & 0.17-4.12 & 0.839 \\
\hline
\end{tabular}

All of the clinical parameters that were measured or examined preoperatively in this study were included. BMI, body mass index; WDAC, well differentiated adenocarcinoma; MDAC, moderately differentiated adenocarcinoma; PDAC, poorly differentiated adenocarcinoma; CCRT, concurrent chemoradiation therapy. 
ety or nation. In addition, given the genetic heterogeneity among the populations that are of Asian ethnicity, susceptibility to VTE may vary among the different Asian ethnic groups.

\section{Conclusion}

In conclusion, the incidence of postoperative VTE, which included asymptomatic cases, was only $3.0 \%$ in Korean CRC patients who were not administered pharmacologic thromboprophylaxis. Symptomatic VTE developed in $<1 \%$ of the patients. Old age, comorbidities, and increased preoperative WBC counts were predictive of an increase in postoperative development of VTE. For Asian patients with CRC, risk-stratified administration rather than routine administration of perioperative pharmacologic thromboprophylaxis should be implemented based on the epidemiologic VTE data from individual countries.

\section{Conflicts of Interest}

Conflict of interest relevant to this article was not reported.

\section{Acknowledgments}

This study was partially supported by research grants from the Seoul National University Bundang Hospital Research Fund (02-2013-093).

\section{References}

1. Kim IG, Kim KH, Seo HJ, Kim JI, Ahn CH, Kim JS, et al. Deep vein thrombosis after surgery for gastrointestinal cancer: incidence and correlation with risk factors. J Korean Soc Vasc Surg. 2004;20:237-41.

2. Kim JW, Chun EJ, Choi SI, Park DJ, Kim HH, Bang SM, et al. A prospective study on the incidence of postoperative venous thromboembolism in Korean gastric cancer patients: an inquiry into the application of Western guidelines to Asian cancer patients. PLoS One. 2013;8:e61968.

3. Shukla PJ, Siddachari R, Ahire S, Arya S, Ramani S, Barreto $\mathrm{SG}$, et al. Postoperative deep vein thrombosis in patients with colorectal cancer. Indian J Gastroenterol. 2008;27:71-3.

4. Choi S, Lee KW, Bang SM, Kim S, Lee JO, Kim YJ, et al. Different characteristics and prognostic impact of deep-vein thrombosis/ pulmonary embolism and intraabdominal venous thrombosis in colorectal cancer patients. Thromb Haemost. 2011; 106:1084-94.

5. Weida D, Patrick LY, Andrew YW. Is it safe to perform operation for colorectal malignancy in Chinese patients without DVT prophylaxis? An 8-year experience from a regional hospital in Hong Kong. Chin Med J (Engl). 2010;123:1973-5.

6. Yeo DX, Junnarkar S, Balasubramaniam S, Tan YP, Low JK, Woon $\mathrm{W}$, et al. Incidence of venous thromboembolism and its pharmacological prophylaxis in Asian general surgery patients: a systematic review. World J Surg. 2015;39:150-7.

7. Yhim HY, Jang MJ, Bang SM, Kim KH, Kim YK, Nam SH, et al. Incidence of venous thromboembolism following major surgery in Korea: from the Health Insurance Review and Assessment Service database. J Thromb Haemost. 2014;12: 1035-43.

8. Mandala M, Falanga A, Roila F; ESMO Guidelines Working Group. Management of venous thromboembolism (VTE) in cancer patients: ESMO Clinical Practice Guidelines. Ann Oncol. 2011;22 Suppl 6:vi85-92.

9. Lyman GH, Khorana AA, Kuderer NM, Lee AY, Arcelus JI, Balaban EP, et al. Venous thromboembolism prophylaxis and treatment in patients with cancer: American Society of Clinical Oncology clinical practice guideline update. J Clin Oncol. 2013;31:2189-204.

10. Geerts WH, Bergqvist D, Pineo GF, Heit JA, Samama CM, Lassen MR, et al. Prevention of venous thromboembolism: American College of Chest Physicians Evidence-Based Clinical Practice Guidelines (8th edition). Chest. 2008;133(6 Suppl): 381S-453S.

11. Shin A, Kim KZ, Jung KW, Park S, Won YJ, Kim J, et al. Increasing trend of colorectal cancer incidence in Korea, 19992009. Cancer Res Treat. 2012;44:219-26.

12. Righini $M$, Perrier A, De Moerloose $P$, Bounameaux $H$. D-Dimer for venous thromboembolism diagnosis: 20 years later. J Thromb Haemost. 2008;6:1059-71.

13. Simonneau G, Laporte S, Mismetti P, Derlon A, Samii K, Samama CM, et al. A randomized study comparing the efficacy and safety of nadroparin $2850 \mathrm{IU}(0.3 \mathrm{~mL})$ vs. enoxaparin $4000 \mathrm{IU}(40 \mathrm{mg})$ in the prevention of venous thromboem- 
bolism after colorectal surgery for cancer. J Thromb Haemost. 2006;4:1693-700.

14. Vedovati MC, Becattini C, Rondelli F, Boncompagni M, Camporese $\mathrm{G}$, Balzarotti R, et al. A randomized study on 1-week versus 4-week prophylaxis for venous thromboembolism after laparoscopic surgery for colorectal cancer. Ann Surg. 2014; 259:665-9.

15. Gould MK, Garcia DA, Wren SM, Karanicolas PJ, Arcelus JI, Heit JA, et al. Prevention of VTE in nonorthopedic surgical patients: Antithrombotic Therapy and Prevention of Thrombosis, 9th ed: American College of Chest Physicians EvidenceBased Clinical Practice Guidelines. Chest. 2012;141(2 Suppl): e227S-77S.

16. Yang SS, Yu CS, Yoon YS, Yoon SN, Lim SB, Kim JC. Symptomatic venous thromboembolism in Asian colorectal cancer surgery patients. World J Surg. 2011;35:881-7.

17. Bergqvist D. Venous thromboembolism: a review of risk and prevention in colorectal surgery patients. Dis Colon Rectum. 2006;49:1620-8.

18. Ay C, Dunkler D, Marosi C, Chiriac AL, Vormittag R, Simanek $\mathrm{R}$, et al. Prediction of venous thromboembolism in cancer patients. Blood. 2010;116:5377-82.

19. Stender MT, Frokjaer JB, Larsen TB, Lundbye-Christensen S, Thorlacius-Ussing O. Preoperative plasma D-dimer is a predictor of postoperative deep venous thrombosis in colorectal cancer patients: a clinical, prospective cohort study with one- year follow-up. Dis Colon Rectum. 2009;52:446-51.

20. Cui G, Wang X, Yao W, Li H. Incidence of postoperative venous thromboembolism after laparoscopic versus open colorectal cancer surgery: a meta-analysis. Surg Laparosc Endosc Percutan Tech. 2013;23:128-34.

21. Kimura Y, Oki E, Ando K, Saeki H, Kusumoto T, Maehara Y. Incidence of venous thromboembolism following laparoscopic surgery for gastrointestinal cancer: a single-center, prospective cohort study. World J Surg. 2015 Aug 28 [Epub]. http:// dx.doi.org/10.1007/ s00268-015-3234-y.

22. Sakon M, Maehara Y, Yoshikawa H, Akaza H. Incidence of venous thromboembolism following major abdominal surgery: a multi-center, prospective epidemiological study in Japan. J Thromb Haemost. 2006;4:581-6.

23. Lee FY, Chu W, Chan R, Leung YF, Liu KH, Ng SM, et al. Incidence of deep vein thrombosis after colorectal surgery in a Chinese population. ANZ J Surg. 2001;71:637-40.

24. Cheung HY, Chung CC, Yau KK, Siu WT, Wong SK, Chiu E, et al. Risk of deep vein thrombosis following laparoscopic rectosigmoid cancer resection in chinese patients. Asian J Surg. 2008;31:63-8.

25. Jang MJ, Bang SM, Oh D. Incidence of venous thromboembolism in Korea: from the Health Insurance Review and Assessment Service database. J Thromb Haemost. 2011;9: 85-91. 